\title{
COMPARAÇÃO DOS TEORES DE COBRE E ZINCO EM LEGUMINOSAS CRUAS E APÓS SEREM PROCESSADAS TERMICAMENTE EM MEIO SALINO E AQUOSO ${ }^{1}$
}

\author{
E. C. B. ANDRADE ${ }^{2, *}$, A. M. BARROS ${ }^{2}$, A. C. P. MAGALHÃES ${ }^{2}$, \\ L. L. C. CASTRO ${ }^{2}$, I. TAKASEI ${ }^{3}$
}

\begin{abstract}
RESUMO
O cobre e o zinco participam de diversas reações no organismo, diretamente ou como co-fatores de enzimas, e são considerados essenciais. Avaliar os teores destes, em leguminosas cruas e após processamento térmico, permite um conhecimento do comportamento destes metais em meio salino e aquoso o que auxiliará no conhecimento do aproveitamento destes pelo organismo humano. Amostras de feijões preto, branco, carioquinha, manteiga, mulatinho, ervilha, lentilha e grão-de-bico, duas marcas de cada tipo e em dois lotes, foram analisadas quanto ao teor total de cobre e zinco quando cruas e processadas termicamente em meio salino e aquoso. A abertura das amostras foi feita por calcinação a $550^{\circ} \mathrm{C}$. As amostras que foram processadas termicamente, passaram por dessecação em estufa a $105^{\circ} \mathrm{C}$ antes da calcinação. O teor total de cobre e zinco nas amostras foi determinado através da espectrometria de absorção atômica em chama. Na análise da rejeição de resultados foram aplicados o teste Dixon e o teste $t$ de Student. Observou-se que, após o processamento térmico em meio salino ou aquoso, a maioria das amostras não teve perda significativa dos teores de cobre e zinco em relação às amostras cruas. Considerando que os teores médios do cobre e zinco nas amostras cruas foram, respectivamente, de $0,75 \mathrm{mg} \%$ e $3,2 \mathrm{mg} \%$ ao ser consumido uma porção média de leguminosas, cerca de $50 \mathrm{~g}$, a mesma fornece aproximadamente $19 \%$ e $10 \%$ das necessidades diárias de cobre e zinco, respectivamente, para um homem adulto segundo a R.D.A.

Palavras-chave: leguminosas; cobre; zinco; biodisponibilidade.
\end{abstract}

\section{SUMMARY}

EVALUATION OF TOTAL AMOUNT OF COPPER AND ZINC BY LEGUMES RAW AND THERMALLY PROCESSED INA AN AQUEOUS AND SALINE MEDIUM Copper and zinc are considered essential oligoelements to human nutrition, taking part in several reactions either directly or as enzymatic co-fators. The amount of these elements in legumes, both raw and thermally processed in an aqueous and saline medium, provides an insight into their behavior, thus allowing an understanding of how these metals are best utilized by the human body. Two different commercial samples of raw and thermally processed (aqueous or saline medium) beans, peas, lemtils and chickpeas, were analyzed in order to determine the amount of $\mathrm{Cu}$ and $\mathrm{Zn}$ present. The opening of the samples was done through calcination at $550^{\circ} \mathrm{C}$. Those samples that were thermally processed went through dissection in a sterilizer at $105^{\circ} \mathrm{C}$ prior to calcination. The total amount of copper and zinc in these samples was determined through atomic absorption spectroscopy on flame. Dixon test and $t$ test by Student were used for the analysis of the results rejection. After thermal processing in an aqueous and a saline medium, it was observed that, almost all samples did not show a significant loss in the amount of copper and zinc, as compared to the raw samples. Considering that the average content of copper and zinc in the raw samples was, respectively, $0,75 \mathrm{mg} \%$ and $3,14 \mathrm{mg} \%$, the consumption about 50 grams, of legumes provides approximately $19 \%$ and $10 \%$ of the daily requirements of copper and zinc for an adult male recommended by the RDA.

Keywords: legumes; copper; zinc; bio-availability.

\section{1 - INTRODUÇÃO}

Os elementos traços, como cobre e zinco, participam de diversas reações no organismo, diretamente ou como co-fatores de enzimas, e são considerados essenciais. Estes elementos devem ser fornecidos ao homem pela alimentação ou suporte nutricional. O processo de absorção destes metais ocorre no estômago e no intestino delgado, onde a absorção máxima ocorre no intestino delgado. Esta absorção ocorre normalmente por difusão ativa, onde estes elementos se complexam a ligantes endógenos e exógenos permitindo assim seu processo de transporte e absorção [9, 13, 20, 21]. As formas solúveis do cobre são absorvidas num teor total de 40 a $60 \%$ do ingerido. Com o zinco, esta

\footnotetext{
1. Recebido para publicação em 20/02/2002. Aceito para publicação em 19/05/2004 (000799).

2. DTA - Departamento de Tecnologia dos Alimentos - Escola de Nutrição, UNI-RIO - Universidade Federal do Rio de Janeiro, Rua Xavier Sigaud, no 290, prédio II, 3o andar - Urca, Rio de Janeiro-RJ, CEP: 20211-O4O. Email: ediracba@unirio.br

3. DQA - Instituto de Quimica, Universidade Federal do Rio de Janeiro (UFRJ).

* A quem a correspondência deve ser enviada.
}

absorção varia de 60 a $70 \%$. A existência de quelados dos elementos traço permite uma eficiência de absorção destes elementos em até $100 \%[4,6,8,9,10,11$, 13, 15, 16,19, 20, 21].

Avaliar os teores destes metais em leguminosas cruas e após processamento térmico irá permitir um conhecimento do comportamento destes metais em meio salino e aquoso o que poderá auxiliar no conhecimento do processo de aproveitamento destes pelo organismo humano.

\section{2 - MATERIAL E MÉTODOS}

\section{1 - Amostras}

Duas marcas e dois lotes de cada marca foram analisados, de amostras de feijão preto, feijão branco, feijão fradinho, feijão carioquinha, feijão mulatinho, feijão manteiga, ervilha, lentilha e grão-de-bico.

\section{2 - Tratamento das amostras}

As amostras cruas após homogeneização foram calcinadas a $550^{\circ} \mathrm{C}$ por um período mínimo de 2 horas. As cinzas foram dissolvidas em $\mathrm{HCl} 2 \mathrm{molL}^{-1}$ e transferidas 
quantitativamente para balão volumétrico de $25 \mathrm{~mL}$. As amostras que passaram por cocção em meio aquoso ou salino, após passarem por dessecação em estufa a $105^{\circ} \mathrm{C}$, foram tratadas de forma similar às amostras cruas [12].

\section{3 - Processamento térmico}

As amostras foram processadas termicamente em meio aquoso e em meio salino $1 \%(\mathrm{p} / \mathrm{p})$ em relação à amostra. O sal utilizado para a cocção foi sal do tipo refinado, sendo o mesmo para todas as amostras. $\mathrm{O}$ processo de cocção ocorreu pelo método convencional utilizando panelas de alumínio.

\section{4 - Determinação do teor total de cobre e zinco}

O teor total de cobre e zinco nas amostras cruas e após processamento térmico foi determinado usando a técnica de espectrometria de absorção atômica em chama [12].

\section{5 - Tratamento estatistico}

$\mathrm{Na}$ análise da rejeição de resultados foi aplicado o teste Dixon e o teste t de Student [5].

\section{6 - Garantia de qualidade}

Na determinação dos teores totais de cobre e zinco, as análises foram feitas em quintuplicada, o aparelho de absorção atômica foi sempre previamente calibrado com soluções analíticas dos respectivos metais.

\section{3 - RESULTADOS E DISCUSSÃO}

Os teores de cobre encontrados nas amostras cruas e após processadas termicamente em meio salino e aquoso se encontram na Tabela 1 . Os resultados foram tratados estatisticamente aplicando o teste t de Student, intervalo de confiança 95\%, e observa-se que em média o teor de cobre nas amostras é de $0,75 \mathrm{mg} \%$. ANDRADE et al. [1, 2, 3], analisando os teores de cobre em frutas, cereais e hortaliças do tipo $\mathrm{C}$, encontrou em média respectivamente os seguintes valores: $0,13 \mathrm{mg} \%, 0,21 \mathrm{mg} \%$ e $0,24 \mathrm{mg} \%$. Estudos mostram que o teor de cobre encontrado em variedades de feijões, espécies Phaseolus vulgaris e Mucuna pruriens, foi de 0,8 a 2,2mg\% [14, 17]. Comparando estes grupos de alimentos com as leguminosas, pode-se considerar que estas são fontes de cobre. Verifica-se que não há perda significativa do cobre após o processamento térmico tanto em meio salino quanto em meio aquoso. Exceções ocorrem para as amostras de feijão branco em meio salino que apresentaram perda de até $24 \%$ e feijão mulatinho em meio aquoso tendo reduzido cerca de $37 \%$ do teor deste metal em relação às amostras cruas.

A Tabela 2 apresenta os resultados encontrados para os teores de zinco nas amostras cruas e após processadas termicamente em meio salino e aquoso. Estes foram tratados estatisticamente aplicando o teste $t$ de Student, intervalo de confiança 95\%, e observa-se que em média o teor de zinco nas amostras é de 3,16mg\%.
Estudos mostram que o teor de zinco encontrado em variedades de feijões, espécies Phaseolus vulgaris e Mucuna pruriens, foi de 2,5 a 10,9mg\%. Em cereais, frutas e hortaliças do tipo $\mathrm{C}$ este mineral se encontra em média, respectivamente, 1,55mg\%, 0,18mg\% e 0,33mg\% $[1,2,3,14,17]$. Observa-se que o teor de zinco nas leguminosas é superior a 10 vezes o valor encontrado nas frutas e hortaliças do tipo C. O processamento térmico tanto em meio aquoso quanto em meio salino não promoveu perda significativa deste metal para a maioria das amostras analisadas. No meio aquoso as exceções ficaram por conta das amostras de feijão preto que teve cerca de $22 \%$ do teor de zinco reduzido e das amostras de feijões branco e mulatinho que tiveram redução do teor de zinco em $15 \%$. No meio salino as amostras de feijão branco e ervilha apresentaram redução do teor de zinco em até $24 \%$ e as amostras de grão-de-bico em até $11 \%$.

TABELA 1. Teor percentual de cobre em $\mathrm{mg} \%$ em amostras de leguminosas cruas e após tratamento térmico em meio salino e aquoso

\begin{tabular}{l|c|c|c}
\hline \multicolumn{1}{c|}{ AMOSTRAS } & Cruas & $\begin{array}{c}\text { Cozidas em } \\
\text { meio salino }\end{array}$ & $\begin{array}{c}\text { Cozidas em } \\
\text { meio aquoso }\end{array}$ \\
\hline Feijão preto & $0,99 \pm 0,13$ & $0,79 \pm 0,22$ & $0,92 \pm 0,06$ \\
Feijão branco & $0,85 \pm 0,14$ & $0,65 \pm 0,11$ & $0,63 \pm 0,20$ \\
Feijão fradinho & $0,84 \pm 0,09$ & $0,72 \pm 0,09$ & $0,95 \pm 0,17$ \\
Feijão carioquinha & $0,69 \pm 0,09$ & $0,57 \pm 0,16$ & $0,75 \pm 0,12$ \\
Feijão mulatinho & $0,75 \pm 0,06$ & $0,59 \pm 0,12$ & $0,47 \pm 0,01$ \\
Feijão manteiga & $0,56 \pm 0,07$ & $0,55 \pm 0,13$ & $0,59 \pm 0,08$ \\
Ervilha & $0,57 \pm 0,04$ & $0,51 \pm 0,08$ & $0,58 \pm 0,05$ \\
Lentilha & $0,82 \pm 0,05$ & $0,73 \pm 0,09$ & $0,85 \pm 0,13$ \\
Grão-de-bico & $0,68 \pm 0,04$ & $0,68 \pm 0,21$ & $0,73 \pm 0,08$ \\
\hline
\end{tabular}

TABELA 2. Teor percentual de zinco em $\mathrm{mg} \%$ em amostras de leguminosas cruas e após tratamento térmico em meio salino e aquoso

\begin{tabular}{l|c|c|c}
\hline \multicolumn{1}{c|}{ AMOSTRAS } & Cruas & $\begin{array}{c}\text { Cozidas em } \\
\text { meio salino }\end{array}$ & $\begin{array}{c}\text { Cozidas em } \\
\text { meio aquoso }\end{array}$ \\
\hline Feijão preto & $3,83 \pm 0,35$ & $3,50 \pm 0,45$ & $2,97 \pm 0,60$ \\
Feijão branco & $3,68 \pm 0,43$ & $2,99 \pm 0,10$ & $3,14 \pm 0,36$ \\
Feijão fradinho & $3,80 \pm 0,27$ & $3,75 \pm 0,24$ & $4,05 \pm 0,38$ \\
Feijão carioquinha & $2,75 \pm 0,14$ & $2,57 \pm 0,52$ & $2,88 \pm 0,48$ \\
Feijão mulatinho & $2,94 \pm 0,20$ & $2,49 \pm 0,47$ & $2,54 \pm 0,26$ \\
Feijão manteiga & $2,36 \pm 0,26$ & $2,61 \pm 0,44$ & $2,46 \pm 0,26$ \\
Ervilha & $2,46 \pm 0,41$ & $1,87 \pm 0,27$ & $2,13 \pm 0,25$ \\
Lentilha & $3,22 \pm 0,81$ & $3,08 \pm 0,72$ & $3,59 \pm 0,58$ \\
Grão-de-bico & $3,38 \pm 0,64$ & $3,01 \pm 0,25$ & $3,23 \pm 0,27$ \\
\hline
\end{tabular}

Os resultados aqui encontrados são similares a outros minerais no que diz respeito a perdas por processamento térmico. DUHAN, KHETARPAUL \& BISHNOI [7], em estudos com ervilhas da espécie Cajanus cajan, verificaram que diferentes processamentos térmicos domésticos não promoviam perdas no conteúdo total de cálcio, fósforo e ferro. 


\section{4 - CONCLUSÕES}

Estima-se como "Ingestão Dietética Diária Considerada Segura e Adequada" (ESADDI - Estimate and Adequate daily Dietary Intake) para o cobre e o zinco os respectivos valores 1,5 a $3 \mathrm{mg} /$ dia e 12 a $15 \mathrm{mg} /$ dia [9, 13]. Considerando que o teor médio de cobre e zinco nas amostras cruas foram, respectivamente, de $0,75 \mathrm{mg} \%$ e $3,2 \mathrm{mg} \%$, ao ser consumido uma porção média de leguminosas, cerca de 50g, a mesma fornece aproximadamente $19 \%$ e $10 \%$ das necessidades diárias de cobre e zinco, respectivamente para um homem adulto segundo a RDA.

Observando os resultados encontrados em relação às perdas dos metais cobre e zinco, em amostras de leguminosas processadas termicamente em meio salino e aquoso, que caracterizaram pouca solubilidade nestes meios, sugerindo a ausência de compostos iônicos destes metais nestas amostras, e que segundo VULKAN et al. [18], a forma iônica, é uma forma do mineral menos disponivel daquela encontrada nos compostos orgânicos. Acredita-se que tanto o cobre quanto o zinco para a maioria das amostras analisadas apresentam boa biodisponibilidade. Estudos complementares de especiação destes metais poderão favorecer na avaliação da biodisponobilidade dos mesmos.

\section{5 - REFERÊNCIAS BIBLIOGRÁFICAS}

[1] ANDRADE, E.C.B.; BARROS, A.M.; TAKASE, I. Avaliação da biodisponibilidade de cobre e zinco em cereais crus e processados termicamente em meio aquoso e salino. Revista Brasileira de Nutrição Clínica, v. 17, n. 3, p. 79-82, 2002.

[2] ANDRADE, E.C.B.; BARROS, A.M.; MELLO, V.S.; TAKASE, I. Determinação dos teores de cobre e zinco em frutas, ANAIS, XVIII CBCTA, ISBN 85-89123-01-4, 2002.

[3] ANDRADE, E.C.B.; BARROS, A.M.; MELLO, V.S.; TAKASE, I. Avaliação dos teores de cobre e zinco em hortaliças cruas e após processamento térmico em meio salino e aquoso, ANAIS, XVIII CBCTA, ISBN 85-8912301-4, 2002.

[4] BARAN, J.E. Química Bioinorgãnica. Madrid: McGrall/ Interamericana de España, 1995.

[5] CHRISTIAN, G.D., Analytical Chemistry, $4^{\mathrm{a}}$ ed, USA, John Wiley \& Sons, 1986.

[6] COzZOLINO, SILVIA M.F. Biodisponibilidade de Minerais. Revista Nutrição, Campinas, p. 87-98, jul-dez, 1997.

[7] DUHAN, A.; KHETARPAUL, N.; BISHNOI, S. Effect of various domestic processing and cooking methods on phytic Acid an HCl-extractability of calcium, phosphorus and iron of pigeon pea, Nutrition Health, v. 13, n. 3, p. 161-9, 1999.

[8] KANNAN, S.; NIELSEN, S.S.; RODRIGUEZ-BURGER, A.P.; MASON, A.C. Iron and zinc bioavailability in rats fed intrinsically labeled bean and bean-rice infant weaning food products, Journal of Agricultural and Food Chemistry, v. 49, n. 10, p. 563-9, 2001.

[9] MAHAN, L. KATHELEEN. Krause: Alimentos, Nutrição \& Dietoterapia, 9a ed., cap. 7, São Paulo: Roca, p. 147-149, 1998.

[10] OLIN, K.; WALTER, R.M.; KEEN, C.L.. Copper deficiency affects selenoglutathione peroxidase and selenodeiodinase activities and antioxidant defense in wealing rats American Journal of Clinical Nutrition, v. 50, n. 3, p. 654-658, 1994.

[11] OLIVEIRA, J.M. A teoria Ortomolecular em Medicina Clínica. Rio de Janeiro, Arte Zen 2000 Prod Gráficos e Visuais, 1995.

[12] OFFICIAL METHODS OF ANALYSIS, Association of official analytical Chemists, $40^{\mathrm{a}}$ ed, USA, 1984

[13] ORGANIZAÇÃO MUNDIAL DE SAÚDE; Elementos Traço na Nutrição e Saúde, cap. 7, São Paulo, Roca, p. 108-122, 1998.

[14] SAMMAN, N.; MALDONADO, S.; ALFARO, M.E.; FARFAN, N.; GUTIERREZ, J. Composition of different bean varieties (Phaseolus vulgaris) of Northwestern Argentina (Region NOA): cultivation zone influence. Journal for Agricultural anf Food Chemistry, v. 47, n. 7, p. 2685-9, 1999.

[15] SANDSTROM, B.; ALMGREN, A.; KIVISTO, B.; CEDERBLAD, A. Effect of protein level and Protein Source on Zinc Absorption in Humans. The Journal of Nutrition, v. 119, n. 1, p. 48-52, 1989.

[16] SHILLS, M. Modern Nutrition in health and disease, 9a ed., Lippincott Willians \& Wilkins, USA, 1999.

[17] VADIVEL, V.; JANARDHANAN, K. Nutritional and antinutritional composition of velvet bean: an underutilized food legume in south India. International Journal of Food Science an Nutritional, v. 51, n. 4, p. 279-87, 2000.

[18] VULKAN, R.; MINGELGRIN, U.; BEN-ASHER, J.; FRENKEL, H. Copper and zinc speciation in the solution of a soil-sludge mixture. Journal of Environmental Quality; p. 193-203, jan-feb, 2002.

[19] WANG, J.; ZHU, Q.; LIU, Z. A primary study on chemical bound forms of copper and zinc in wheat and rape, Ying Yong Sheng Tai Xue Bao, v. 4 n. 11, p. 629-30, 2000.

[20] WAPNIR, A.; STIEL, L. Intestinal Absorption of Copper: Effect of Sodium. Proceeding of the Society for Experimental Biology and Medicine, v. 185, n. 3, p. 277-282, 1987.

[21] WAITZBERG, D.L. Nutrição Oral, Enteral e Parenteral na Prática Clinica. $3^{a}$ ed., São Paulo,Editora Atheneu, p. 131-134, 2002. 